\title{
Putting the Emerging Commercial Sub-orbital Industry to Work for Engi- neering Education
}

\section{Dr. Steven H. Collicott, Purdue University, West Lafayette}

Professor Collicott has led the proposing, design, and construction of 32 low-gravity NASA aircraft experiments, designed 2 of 6 tests in the successful Capillary Fluids Experiments (CFE) performed in the International Space Station in 2006/07, and advised on CFE modifications launched in April 2010. In 2012 he was selected by NASA as PI on the Fluids Education payload for ISS, a new science payload and program in conjunction with a colleague at another school. He is viewed as a leader in pursuing new fluids dynamics research opportunities that are becoming available shortly in the commercial sub-orbital rocket industry. He is one of three researchers selected for early flights with Blue Origin with an NSF-funded payload, and he is also launching payloads with Armadillo Aerospace, Masten Space Systems, XCOR, and Exos. Professor Collicott began activities in innovative teaching in capillary fluid physics, in STEM $\mathrm{K}-12$ outreach, and in placing the positive news of university engineering education and capillary fluids research in the national media in 1996. In 1996 he created, and still teaches, AAE418, Zero-Gravity Flight Experiments, at Purdue. The research activities of Prof. Collicott's undergraduate students have been shown in The New York Times, Wall Street Journal, Fox News NY, Good Morning America, Chicago Tribune, Via Satellite, and a multitude of local television, print, and radio markets. 


\title{
Putting the Emerging Commercial Sub-orbital Industry to Work for Engineering Education
}

\begin{abstract}
Low-cost re-usable commercial sub-orbital rockets are beginning to fly for space tourism and for research and education missions. This emerging industry, which for now is unique to the United States, is presenting new opportunities for engineering education. Rockets to fly with and without human occupants are being built by a handful of companies, and thus numerous types of flight opportunities are becoming available. The educators who choose to now make use of this new flight capability may find fertile ground for both teaching and research. Even one fifthgrade teacher in the U.S. has recently purchased flights for his students' payloads, so engineering educators are already at risk of being left behind by our grade school colleagues. Lessons learned are shared to aid the others who will seek now to include sub-orbital rocket flight into their curriculum.
\end{abstract}

Introduction

This paper highlights a new, to date largely under-publicized, and affordable teaching opportunity to the engineering community and also highlights a formal course for undergraduates as a mechanism for enabling student achievement. Virgin Galactic certainly excels at advertising their upcoming flight service but there are a handful of other companies also seeking to enter the market. Most of these other companies have not pursued publicity to such an extent during the vehicle development years. Thus most of the companies and flight vehicles which will soon be available, and the one already available, are largely unknown within the engineering education and even within the specialty of aerospace engineering. To highlight the educational nature of these emerging flight services, this paper reports on the author's teaching activities in which an existing design-build-test class focusing on zero-gravity flight experiments is adapted to provide undergraduate student designed and built payloads for launching in the commercial sub-orbital industry. This class enables spending, fund-raising, faculty time commitments, and student participation. Payloads launched to date on test flights of these rockets are described along with lessons learned for student payload design and flight. Payloads under development and the class structure which enables this work are also described. Feedback on the in-class experiences are gathered from recent alums and will be shared and discussed.

Any engineering professor who persists in this career for a number of years has observed that teaching and research duties generally overlap. For example, a professor's research discoveries or lessons learned give him or her deeper and unique insights into the topic which then lead to updates of lectures and classes. One also sees that a well-presented topic or class can stimulate some of the undergraduate students to consider graduate school and research as a career path for the first time. Embracing this overlap can lead to a professor teaching research to undergraduates as an established, long-running class. In such a situation, the topics for the class 


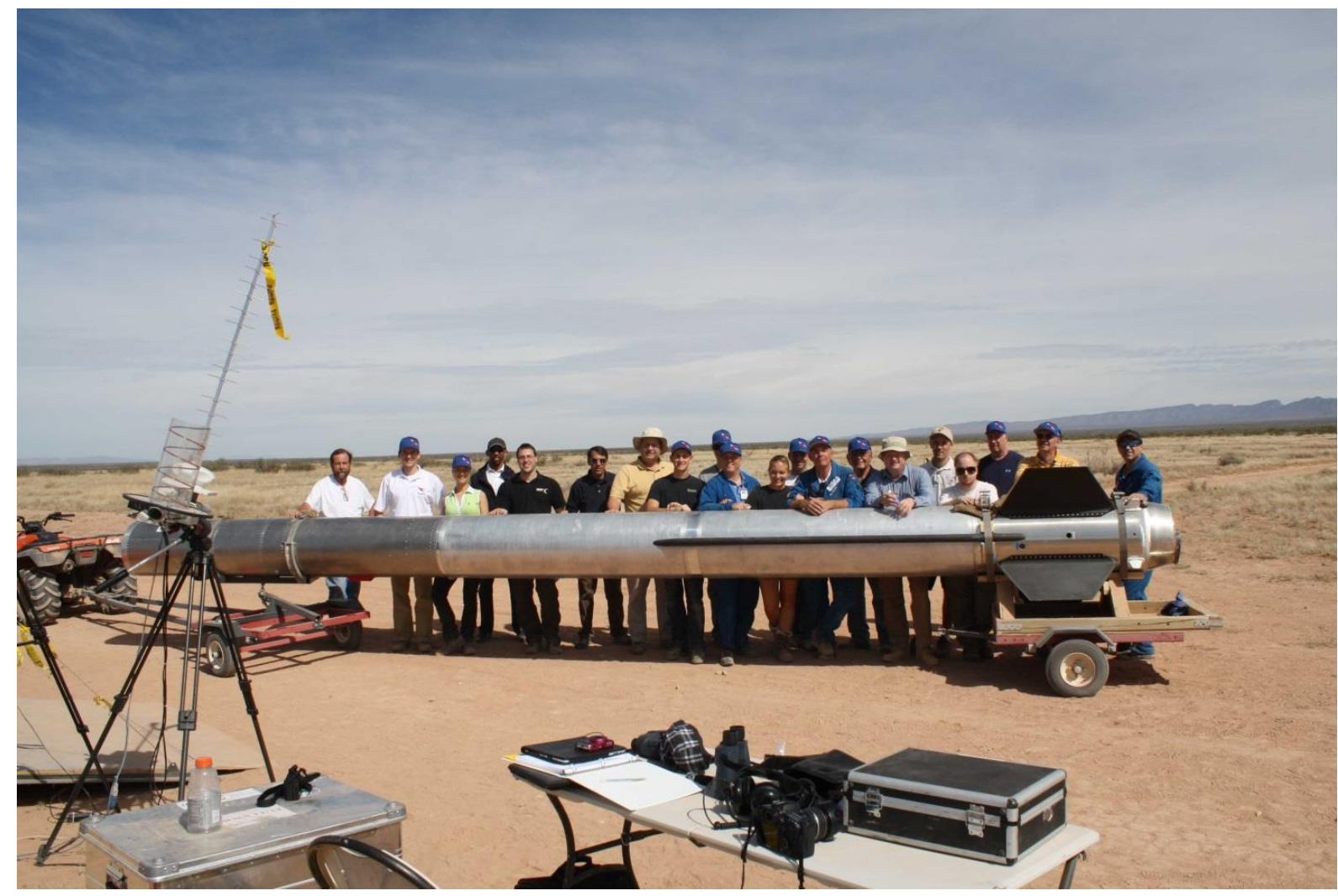

Figure 1. Post-flight photograph of Armadillo team and two payload teams, one consisting of Purdue undergraduate students in Aeronautics and Astronautics at the vertical launch facility of New Mexico Spaceport America. The blue hats celebrate this launch as the first FAA licensed commercial sub-orbital rocket launch from New Mexico Spaceport America, October 6, 2012.

are driven by the professor's research interests. Thus, the author and the author's institution have created a long-running undergraduate project (design-build-test, hands-on, experiential, etc.) class to maximize the benefits that our students can obtain from participating in real-world off-campus aerospace projects and competitions. The latest addition to the opportunities in this class is student-built experiments for commercial sub-orbital rocket launches. As the commercial sub-orbital market is, at this writing, merely in an emerging state, formal pursuit of course objectives sometimes is sacrificed to the need to secure launch opportunities and deliver on them as they arise in various forms. There is no steady state in the field right now and thus adaptability is key to providing students with the most opportunities for gaining hands-on, teambased, real-world, aerospace engineering experiences.

Access to certain environments for research and education purposes has traditionally been limited. For example: deep ocean trenches, Antarctica, the Mesosphere and Lower Thermosphere (above all balloons and below all satellites), Earth orbit, and weightlessness (known colloquially as "zero-gravity") of durations greater than 20 seconds. The emerging U.S. 
commercial sub-orbital rocket industry is beginning to provide a unique solution ${ }^{1}$. One example of these modern commercial vehicles is a fully-reusable liquid rocket with green propellants, gentle lift-off, and GPS-guided parachute return to the launch pad area for payloads only, not for human flight, which further reduces costs. These new rockets are being developed with private capital; they are fully commercial ventures, not government programs. Access to launch is therefore through a purchase, not through agency peer review. One U.S. company has posted a price list on line which makes clear that the cost for access to space is now approximately $0.4 \%$ of the typical cost for an experiment launch on a traditional NASA or ESA sounding rocket and also provides the option of the researcher flying with the payload in a piloted winged rocket powered vehicle.

The author's design-build-test course began in its most basic form in 1997 in response to NASA's inaugural nationwide Reduced Gravity Student Flight Opportunities Program. The RGSFOP, which was renamed a few years ago to be the Reduced Gravity Educational Flight Program, or RGEFP, has long been viewed as NASA's best university-level educational activity. The RGEFP is absent for the 2014-2015 academic year, replaced by an interesting low-gravity design-build-test task involving asteroid sampling technology for use by astronauts. RGSFOP activities in the course have been described before ${ }^{2,3}$ and thus are not discussed herein. Presently the course is offered every semester including summer. Enrollment in spring 2015 is 40 students and the course is increasing to 60 students in fall 2015. Summer enrollment is typically smaller as fewer students are on campus. Yet launch schedules remain, so the fewer summer students perhaps experience more of the various in-class activities than spring and fall semester students. Since 1998 over six hundred students have participated in these activities at Purdue University.

\section{Payloads}

To date there are payloads built or being built for flights on, alphabetically, Armadillo Aerospace, Blue Origin, Exos Aerospace, Masten Space Systems, UpAerospace, and XCOR rockets, NearSpace balloons, and a student rocket project. Sponsorship of these activities is varied so is outlined in the individual descriptions below but hardware costs have largely been supported by our college of engineering as one part of the process to keep laboratory classes upto-date. Descriptions of these activities that put the new flight capability to work for education begin with payloads that have flown and then payloads in development. Flight provider capabilities are found at the web sites for the companies. These sites are easily found in any web search engine and thus not referenced here.

1. Armadillo Aerospace: Beginning in 2009 Armadillo and the author collaborated to launch student payloads on Armadillo test flights, see Figure 1 for a post-flight photo. The ability to work with a 'prototype research customer' was attractive from a business development standpoint. Armadillo employees also expressed a pleasure in working with students as perhaps helping to create the next generation of rocket engineers. The 


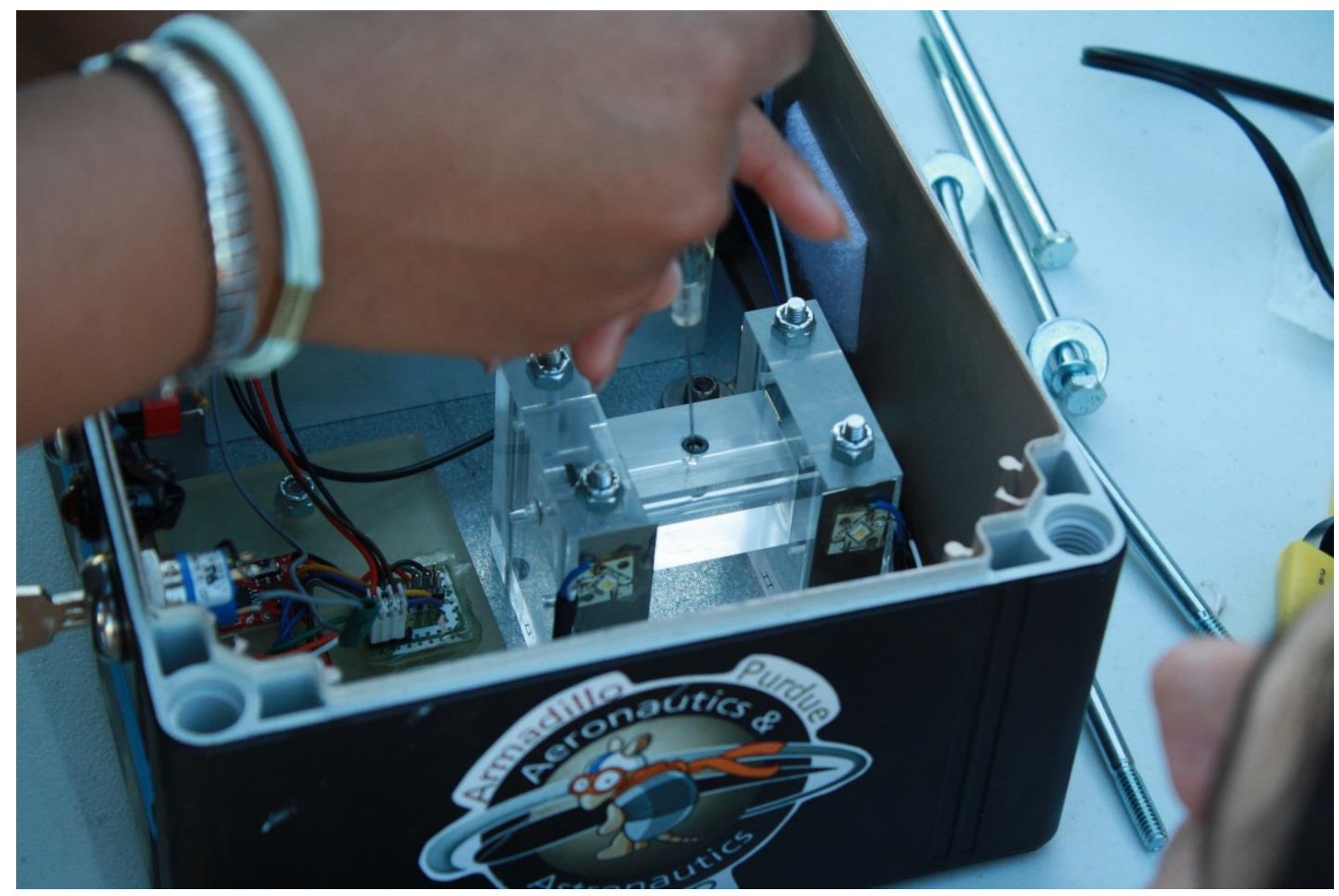

Figure 2. Example of Purdue Aero-Astro undergraduate students preparing their payload for the Armadillo launches.

Armadillo payloads, such as in Figure 2, were designed to be fully automated with no interaction with the rocket other than being bolted to the rocket. That is, no trigger signals or power from the rocket. The purpose in choosing such isolation is that it freed us to build what we needed and freed the rocket company from needing to develop electrical interfaces and procedures earlier than desired. Thus an accelerometer was used to sense either the boost of the vehicle or sometimes the erection from horizontal transport to vertical installation on the launch rail. This detection was detected by a controller and used as the trigger to on the payload. An Arduino Uno was typical for our controller in these payloads.

Armadillo was a great partner and launched various payloads from the vertical launch facility at New Mexico Spaceport America which gave us our immersive education in remote launch-site operations for science payloads. This collaboration also led to important advances in our payload development capabilities. Armadillo closed down in 2013 after taking one of our payloads to $95 \mathrm{~km}$ altitude in a low-cost, green (LOX and ethanol), reusable, non-spinning, rocket developed for the science market. 
2. NearSpace: A series of three high-altitude balloon launches of a glider are aimed at developing upper stratospheric parabolic flight capability for smoother periods of weightlessness than at lower altitudes. The flights are purchased by NASA through the Flight Opportunities Program in STMD following their standard competitive proposal process, not a student or educational program. The first flight was in summer of 2013 and we flew a student designed and built payload, see Figure 3, to measure accelerations and temperature in the payload bay of the glider and also flew a passive low-gravity fluids demonstration payload. Three axes of acceleration and temperature data were acquired in the first flight but the flight itself was not as desired so these data lack relevance. The payload has been improved, re-tested, delivered, and awaits a second flight. At this writing this second flight is believed to be imminent.

3. Masten Space Systems: A payload is prepared and awaiting flight on a Masten vehicle. This payload studies a simple capillary stability problem in fluid physics. As Masten's lunar lander type of vehicle and flight capabilities have found customers for exploring planetary landing and related guidance, control, algorithms, etc., this type of flying is a

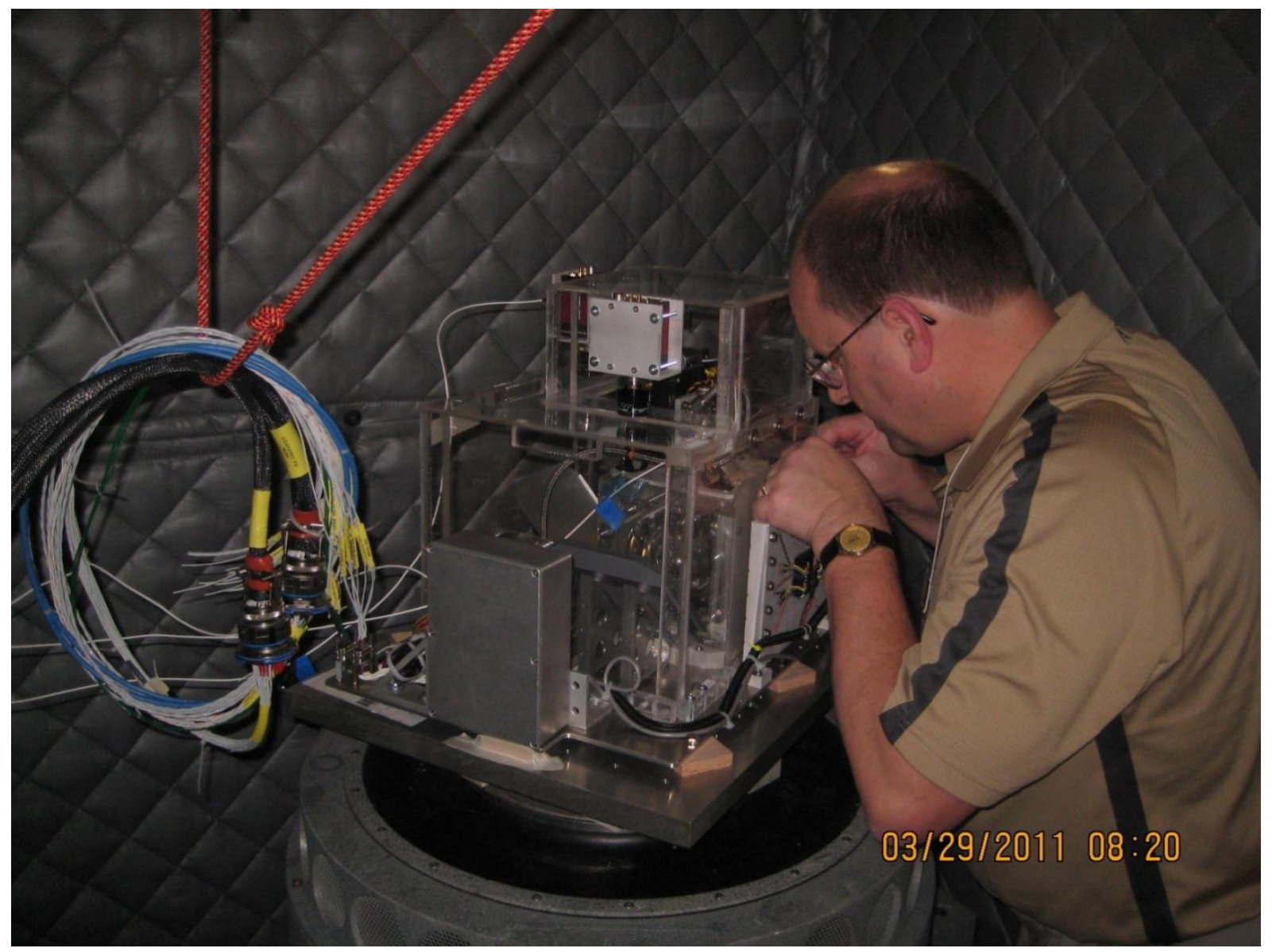

Figure 4. Blue Origin payload on a vibration test table prior to the successful vibration test. Final preparations being made by the author. 
high priority for them. We await their return to pursuit of vertical flight after their successful business ventures in largely horizontal flight.

4. Blue Origin: the author was selected in 2009 as a "Pathfinder" experiment for Blue Origin to help them explore how to work with the science market. Their vehicle is intended for both tourism and research. The payload is to study critical wetting phenomena in non-cylindrical geometries where the sound mathematical basis for cylindrical geometries is lacking. Construction was supported by the National Science Foundation and the author's college of engineering. Figure 4 shows the payload being prepared for vibration testing. Presently undergraduates are working to update the highdef camera system, define operations, and prepare training and ground procedures.

5. XCOR: Early in 2011 an agreement was reached with XCOR to provide a student-built atmospheric study payload to fly in the smallest payload chamber on their Lynx vehicle. This is a $2 \mathrm{U}$ cubesat size and can be open to the atmosphere at altitude. Mesosphere and lower Thermosphere science is expected to be one of the first big markets for this new class of rockets. These parts of the atmosphere are above every balloon and below every satellite, so data from these altitudes are scarce compared to other layers of our

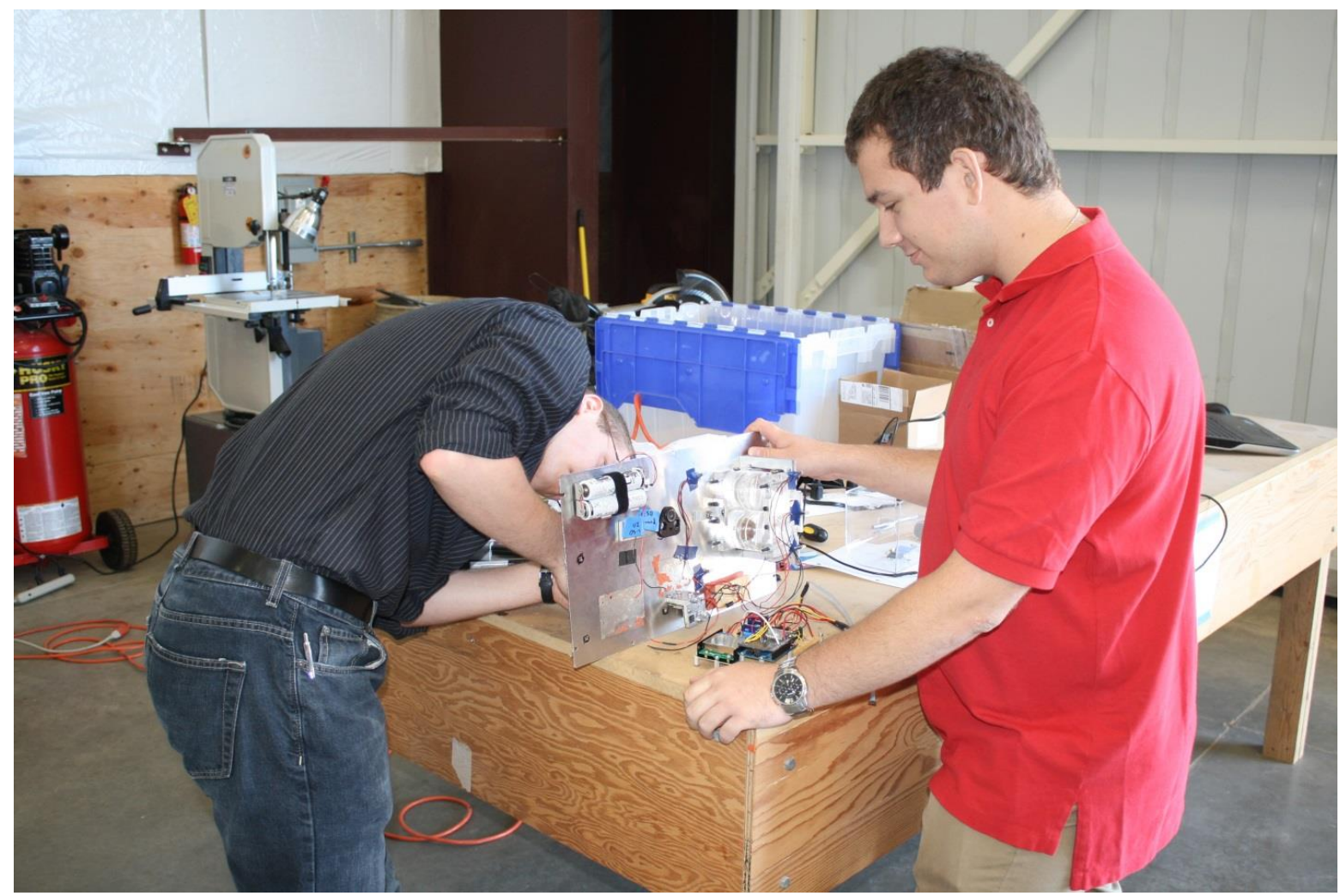

Figure 3. Purdue Aero-Astro undergraduate students preparing the payload for NearSpace upper stratospheric balloon-launched glider flights, June 2013. 
atmosphere. The student payload is sampling pressure with a vacuum transducer, temperature with RTDs, because volume, mass, and power remained available, viewing with a camera during coast. Payload delivery is expected in the fall of 2015. Students are building the structure, selecting components, building power distribution and data acquisition electronics, and similar. On-line price lists show that anyone's $2 \mathrm{U}$-sized payload can fly for $\$ 20 \mathrm{k}$; no government agency down-select, no adapting to someone else's priorities, just your payload developed for your needs, from grade school adventures to $\mathrm{Ph} . \mathrm{D}$. research.

6. Green propellant testing: NASA Flight Opportunities Program award the author one flight on the solid-fueled UpAerospace SpaceLoft vehicle to demonstrate low-gravity surface tension control of a recently developed green propellant in weightlessness. This payload is 10 inch diameter, 10 inch tall and is student designed, built, and will be student integrated and operated. Figure 5 shows a few pieces already machined and Figure 6 shows the overall layout on one of two end disks of the cylindrical payload container. This payload is to launch late summer of 2015. This work complements NASA's Green Propellant Infusion Mission by testing a different form of propellant

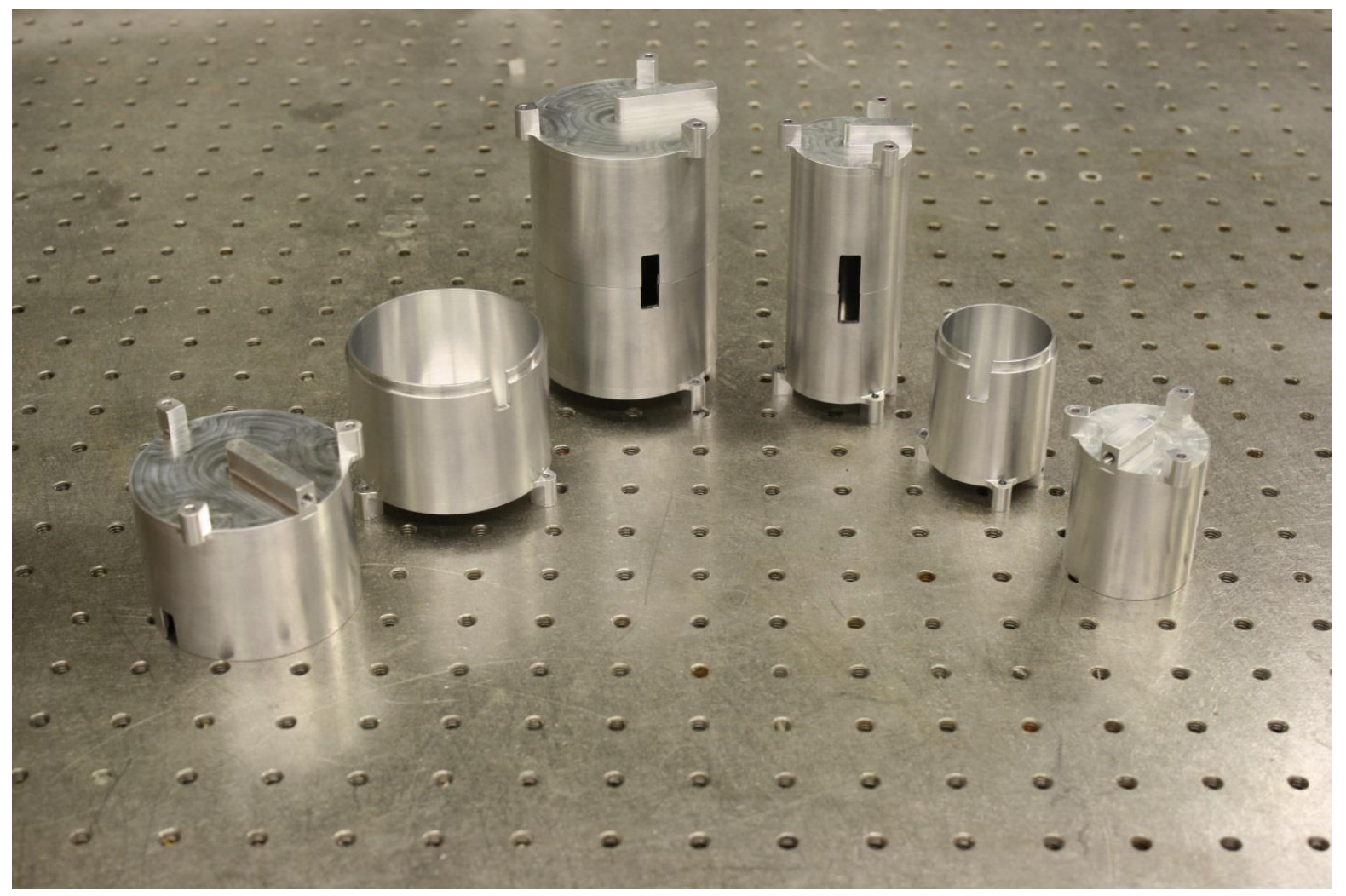

Figure 5. Purdue undergraduate Aero-Astro student-designed reservoir halves for a NASA green propellant low-gravity test. Each whole unit, like the two in the center, holds two reservoirs actuated by two pistons simultaneously to both drain liquid form the tanks and replace that liquid volume with air so as to keep air pressure in the tanks constant. 
control in weightlessness that GPIM is using.

7. Exos Aerospace: Portions of the old Armadillo Aerospace team have secured financing and are moving ahead with the green, liquid-fueled, reusable, GPS-guided parachute return to the launch site, non-spinning science rocket that Armadillo had left off with. Our students are designing, analyzing, and building a prototype payload rack plus instrumentation for sampling temperatures in the sealed test volume and to monitor static pressure to document good sealing form the outer atmosphere.

8. Capillary advance: another payload for launch on XCOR, with an anonymous sponsor to date, will investigate the feasibility of a specific new capillary fluids experiment design for the International Space Station. The fluid physics of interest require the long duration very high quality zero-g onboard ISS so this sub-orbital flight is to deliver risk reduction steps in the hardware design and operations. Three minutes of the sub-orbital weightlessness cannot possibly deliver the science in this topic but it can most definitely advance the program by documenting good performance in creating the desired initial condition in ISS and also test the post-processing of video data. This payload is to occupy the region behind the pilot's seat and inside of the pressurized cockpit.

The absence of one major company, Virgin Galactic, from the payload list is coincidental. Like XCOR and Blue Origin, Virgin Galactic will fly people to sub-orbital space. These three companies will provide an interesting opportunity for researchers to fly with and perform their experiments in weightlessness. This should be a strong tool for some topics and likely not be that important for other topics. Flight cost is increased substantially over automated payloads so human-tended payloads may be less appealing to education budgets.

\section{Lessons Learned}

The list below is intended to aid other faculty in pursuing similar opportunities.

1. The skills that students bring to the class are not constant; they change on about a threeyear time scale. Class content needs to adapt to accommodate different inputs and to address evolving outputs, such as new or mature payload interfaces. For example, we presently see a strong decay in basic coding experience in upper-level undergraduates and thus tasks like programming a controller or creating a 1-D numerical model for the science behind the payload are not the simple tasks they were a few years ago. On the good side, their CAD skills are stronger than three years ago. The professor must seek to recognize the collective skill set early in the semester so as to fill the voids before the voids slow down the project.

2. The sub-orbital industry is young, companies come and go, vehicle dimensions and interfaces change, so keep adaptability in mind as you design an experiment. 
3. A teaching machine shop is great for teaching but is not a dependable source for timely production of quality hardware. Similarly, a precision CNC mill has very poor precision when students fail to clamp a piece into a vise or jig properly. Therefore, when purchasing inexpensive materials, anticipate a shockingly large scrap rate. For parts with expensive materials, hire a professional shop.

4. It is clear that the thumb-centric communicators who presently dominate our undergraduate population benefit greatly from the experience of simple face-to-face interpersonal communication with teammates, machinists, technicians, launch company engineers, purchasing clerks, and others. In addition, be clear when giving communication instructions, e.g., the author finds these days that when giving the instruction "talk to the electronic technician about choosing a solid-state relay" he needs to emphasize that the verb "talk" still means that your mouth moves and sound is emitted. Many students are eager to distort "talk to" so as to suggest that they email the person rather than meeting this person for the first time and starting a face to face discussion. When students become alums and go to work, especially in a large aerospace company, there are many strangers on the team and the ability to meet them and rapidly begin to work with them is important to success.

5. The vibration levels in these new sub-orbital rockets are much lower than one usually thinks of for launching to orbit. Simpler, lighter weight payloads containing a larger fraction of off-the-shelf components are possible. The greatest vibrations at the top of a household washing machine are perhaps representative of flight on a sub-orbital liquidfueled rocket. Thus, shipping your payload from the university to the launch site by truck may be the harshest vibration environment that your payload experiences. This may be distressingly harsh so design durability into your hardware.

6. The mesosphere and lower thermosphere are very cold. But a rocket ascending rapidly, supersonically, through the atmosphere can have substantial aerodynamic heating. Learn early in your program if there are either cold or hot conditions in the payload section during the flight and design accordingly.

7. The new generation of high-definition video cameras that grew out of the extreme sports world is excellent for student payloads. They are affordable and many hours of video can be recorded on the micro-SD cards. However, these cameras are often the primary power user and heat producer in a student payload so design with care. Aside from the wellknown consumer cameras, a little on-line shopping will bring you to equivalent cameras with screw terminals for power and trigger signal, screw holes for secure mounting within the payload, and also interchangeable lenses for approximately the same low price. 


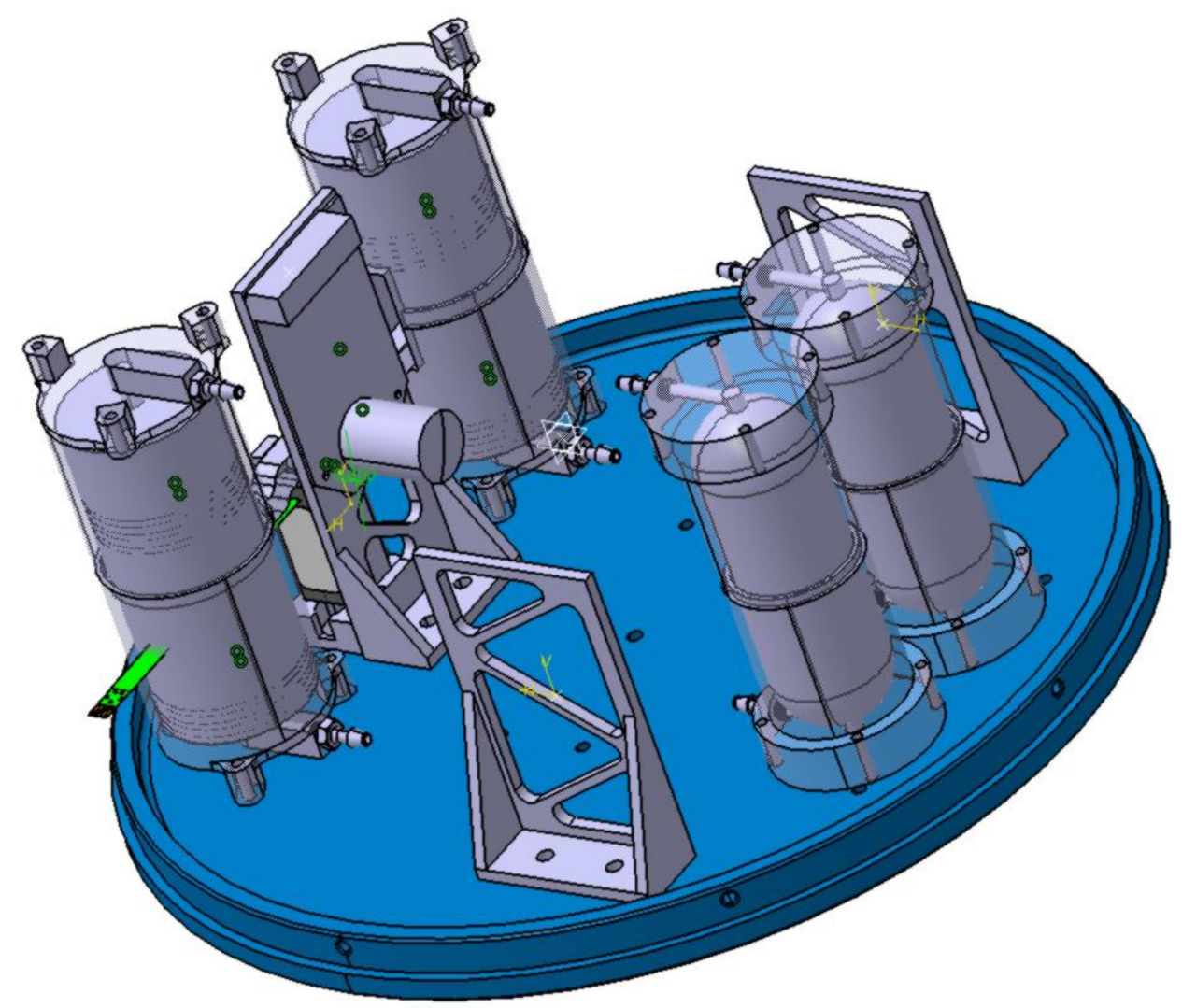

Figure 6. Solid model of one of two 10-inch disks to be joined to create the payload cylinder. The hardware on the other disk is highly similar in external appearance but models a different type of spacecraft liquid propulsion components.

8. Different flight providers have different battery preferences. Talk to them early. Hot versus cold and pressurized versus vented payload sections often drive the battery choice. Be aware of prohibitions against air-freight for your batteries and ground-ship a new set to your flight provider or launch site sufficiently early. High efficiency DC to DC voltage converters are abundant and affordable so don't waste time arguing about battery choices.

\section{Conclusions}

The commercial sub-orbital industry is ripe for exploiting by engineering education. The typical budget and duration of a program, from conception to launch, both fit the typical student needs easier than small satellite programs do. This does not suggest replacing small-sat programs but rather it suggests projects in parallel with small-sats thus involving an even larger group of students.

Impact on students and their careers is most commonly documented in emails from young alums. In the most recent two instances from the last month, alums described the class as "life 
changing" and a "big part" of securing a "dream job". Student tasks in the class vary widely depending on payload type, collective expertise of the students entering the class (a wealth or absence of electronics or machining expertise, as examples,) schedule demands, payload science topic, and launch provider (e.g., are students working with a mature payload interfacing protocol or an evolving one?). The goal is to capitalize on these random opportunities for the random sampling of student expertise that walks in the door, and thus a steady-state style of focused class or student outcomes has not yet become a productive educational path.

Some deride the commercial sub-orbital industry as merely providing "joy rides for rich guys," but note that those joy rides are financing the development of the vehicles which research and education users are essentially paying only the recurring costs of flight operations. Thus, the cost for spaceflight experimentation is now sufficiently low for frequent educational launches. In addition to the university-level engineering focus, in the near future, AreteSTEM and other opportunities will be flying K-12 and perhaps university payloads on various vehicles. The cost of a K-12 payload will soon be less than the cost of a new set of football uniforms for the high school team and the duration of an entire program can fit within a school year.

Now is the time for creative engineering professors to become early adopters of this emerging capability. Those who do can provide students with opportunities for spaceflight that complement the small-sat programs by providing shorter duration hands-on real-world teambased engineering education projects. In 2010 the Deputy Administrator of NASA, in a keynote address at the Next-gen Sub-orbital Researchers Conference ${ }^{4}$, described the author's zero-gravity design-build-test teaching efforts: "These are the kinds of things that NASA should be doing, that we say we're doing, and that the President has asked us to do, and we need to continue."

Professors often voice to the author a sentiment such as, "I wish I could teach a course like this at my university." Discussion then shows that they generally have not yet tried to do so. The first step is for a professor to try. In other words, until your department head or curriculum committee dictates to you "No" then you are the one blocking the creation of the course. Institutionalizing the educational opportunity from sub-orbital rockets, NASA's RGEFP, or other design-build-test competitions enables students and professors alike to commit time to produce quality results.

\section{Acknowledgements}

The author is grateful for support from NASA Flight Opportunities Program, Armadillo (now Exos), Masten, XCOR, Northrop-Grumman, a National Science Foundation EAGER grant, and the gracious alumni of this course, AAE418 "Zero-gravity Flight Experiment" who donate to support subsequent undergraduate team travel. In addition, three consecutive Department Heads in the School of Aeronautics and Astronautics and three consecutive Deans in the College of Engineering at Purdue University have been avid supporters of these educational endeavors. 


\section{Bibliobgraphy}

1. Stern S. A., "Commercial Spaceflight Companies Will Revolutionize Space Science," Scientific American, 308:69-73, 2013.

2. Collicott, S. H., "An Undergraduate Project Course for the NASA Reduced Gravity Student Flight Opportunities Program," 39th AIAA Aerospace Sciences Meeting and Exhibit, Reno, NV, January 2001. AIAA-2001-0585.

3. Collicott, S. H., "Purdue Student Experiments and Education in Various Low-Gravity Flight Methods," 49th AIAA Aerospace Sciences Meeting including the New Horizons Forum and Aerospace Exposition, Orlando, Florida, Jan. 4-7, 2011. AIAA-2011-538.

4. Garver, L. B., "Keynote Address," NASA Next-Generation Suborbital Researchers Conference, Boulder, Colorado, February 18, 2010. Transcript presently accessible on NASA web site: http://www.nasa.gov/pdf/428838main_Garver_Suborbital_Conference_0218.pdf 